\title{
The Appreciation Education of Western Arts
}

\author{
Yan Wang \\ Design school \\ South China University of Technology \\ Guangzhou, China
}

\begin{abstract}
The ability of art works appreciation has become an important course in quality education due to the needs of talents development in the new era. This paper starts from the appreciation education of arts in comprehensive colleges and focuses on art appreciation education of non-art major students, especially the appreciation of western arts, incorporating the viewpoint of “beauty" into art appreciation, analyzes and explores the methods and arguments in art appreciation with guiding function.
\end{abstract}

Keywords-art appreciation; western art works; artistic language

\section{INTRODUCTION}

The appreciation of western painting not only contains the understanding of visual material constitution of painting like techniques and materials, but more importantly lies in the style of expression, the theory and concept of art, etc. In addition, explaining the spiritual elements of the work like the theme and concept also need to be based on the religion, cultural connotation and literary ideas of that time. The internal performance and deep symbolic significance are the important basis for the painter's ideological tendency and creative ideas. The painter's technique and expression constitute the artistic language of every painter, forming the artist's artistic conception.

First, let's take a look at the two pieces below. Da Vinci's "Mona Lisa" in "Fig. 1" and Picasso's "Girl Playing Mandolin" in "Fig. 2", known as the modern version of Mona Lisa.

Project source: Guangzhou "13th five-year" philosophy and social sciences development planning 2016, 2016GZGJ29

Characteristic innovation projects of colleges and universities in Guangdong (educational research project) 2016GXJK006

2017 fundamental research funds for the central universities $\mathrm{x} 2 \mathrm{sjC} 2170100$

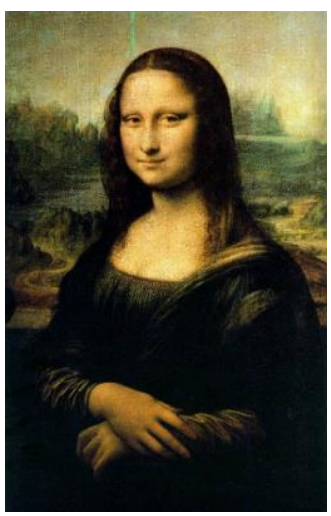

Fig. 1. Da Vinci’s "Mona Lisa".

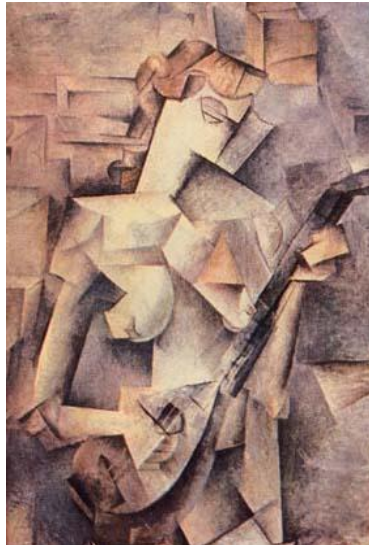

Fig. 2. Picasso's "Girl Playing Mandolin".

Visually, "Mona Lisa" is obviously a painting that attempt to portray the real character. The work depicts an elegant female image with the standard 3/4 sides, and shows the inherent charm of portrait painting with her eternal smile. Adding the background description with perspective sense, Da Vinci pushed the technique and style of realistic painting to an unprecedented height.

Compared with "Mona Lisa", "Girl Playing Mandolin" is abstract obviously. However, it is more real from certain perspective according to the author. Da Vinci depicted the character from a fixed point of view, fixing a fixed moment; while Picasso abandoned the traditional perspective, trying to display all aspects of the characters on a picture. True reality should be the all-round performance, so Picasso's works have more real performance in the concept. 
Erwin Panofsky (1892-1968) regarded the appreciation of art works as a recreation of art. Through the imagination and creativity of the appreciator, the works were endowed with new meanings. "It depends on the innate feelings and visual training of the viewer, and depends on his cultural accomplishment" (see Note 1). From this we can understand why there are one thousand Hamlets in the eyes of one thousand audiences, which is the re-creation of the art works by the viewer in their appreciation.

\section{FACTORS AFFECTING THE APPRECIATION OF ART WORKS}

\section{A. Theme and Creation Process}

In the process of appreciation of art works, the understanding of the theme of the work is of great significance. As pointed by Panofsky in "Studies in Iconology", he divided the themes of art works in the Renaissance mainly into three categories: (1) existing contents in nature that are popular and easy to understand; (2) biblical stories, myths and fables that are familiar to people; (3) contents with symbolic meanings.

Compared with the classical realistic painting which is easy to be understood, modern painting, whether it is character modeling or background processing, is difficult to find the corresponding thing in reality. The relationship between the process of creation and the image is mainly reflected in the theme of the work and the interpretation of the theme. There are three stages in the exploration of the relationship between theme of work and the theme of the painting for modern and contemporary paintings. The first stage is related to realism, impressionism and brutalism; the second stage is related to expressionism, symbolism and super realism; and the third stage is related to abstract, abstract expressionism, op art, pop art and conceptual art. Especially in the third stage, the painter's unconscious world view runs through the whole process of the creation till finish, and has great relationship with the image and shape.

When an expression theme is decided, how to perfect the theme into a painting work is the process of painter's creation. According to Johannes Volmert's (1848-1930) theory, artists, in a certain order and art form, continue to combine a variety of performance materials. During the process, painter combines his own artistic accomplishments, experience, ability and inspiration with materials and style. His body, emotion and unconscious movement combine with the painting materials and techniques. Relying on art language like color and shape, the author gradually perfects the theme and thus a piece of work is made through constant thinking.

\section{B. Subjective Factors of the Painter}

In the process of creation, painters often think about their own works and how to make the viewer understand the meaning of the work. After continuous modification, his feelings and intentions can be expressed. "Express" is the representation of the work's academic value. Based on the "expressed" contents of the works through techniques and concept, works can be divided into several levels judging from whether it is his own creation, factors affected, reference, and quote, imitation and plagiarize. Originality can be regarded as the highest value of fine art works.

"Representation" presents the form and style of the work, which is related to the painter's personality and quality. As for the quality of the painter, Viktor Lowenfeld (1903-1960) summarized in "Creative and Mental Growth" through the experiment testing children's performance toward modeling that $47 \%$ of the children conveyed their visual intention by visual sense, $23 \%$ of which were conveyed by sense of touch, and the remaining $30 \%$ were the type mixing between the two.

Carl Gustav Jung $(1875$ - 1961) proposed introvert type and extravert type first in "Psychological Types". Then he combined the four functional types of thinking, feeling, feeling and intuition with introversion and extroversion and formed eight personality types: extroverted thinking type, extroverted feeling type, extroverted intuitive type, extroverted sensation type, introverted thinking type, introverted feeling type, introverted intuitive type, and introverted sensation type, and thus concluded the rational type of "thinking and feeling" and irrational type of "intuitive and sensation".

\section{Subjective Factors of the Viewer}

Art works are different in making methods and materials in different times. Artists use the materials and techniques of their time to carry out subjective creation. Viewers of different times will have different understanding of the same art work. This kind of appreciation has a certain distance with the plot in the art works, and it is also separated from the trivial things of daily life. As said by Immanuel Kant in "Critique of Judgment" that it needs distance to appreciate beauty. Beauty is a pure act of consciousness. Painters can present their own knowledge in the picture and show them to the viewer, and the viewer can have their own understanding toward the work. Both of them need creativity and insight. The reason why those art works recorded in the art history can be called masterpiece are that, on the one hand, the work itself has profound significance in the times it produced, including the experience of the painter, the theme of the painting, painting techniques, painting materials and so on; on the other hand, viewers of different times have more diversified interpretation of the work in the appreciation process, so that these works have more and deeper meaning, thus highlighting the historical value of the famous works.

To sum up, whether concrete, intentional or abstract art works, there should be the subjective creativity of the painter, but also the independent and active aesthetic space for the viewer, which is so called "different people have different views".

\section{Understanding Different Styles and Genres}

According to the theory of Herbert Read, a British art educator, not every painter and genre can be clearly classified, painters always influence each other. Under this premise, Read classified some of the most important genres in Modern Art. For example, realism $=$ thinking type, super-realism $=$ feeling type, expressionism = sensational type, and constructivism = intuitive type. This kind of classification can give us a general distinction in appreciating works to some extent, so as to grasp 
the classification of the works as soon as possible. After the second half of 19th Century, modern painting, found by French romanticism and impressionism, gradually faded the plot narration of myth and religious stories in classical painting. Painting goes to the non narrative form of symbols, and painters' self-expression and personalized style become the mainstream of art.

\section{E. Understanding the Techniques of Art Works}

Take classical painting as example, such as Botticelli's "Spring" in "Fig. 3", Da Vinci's "Mona Lisa" and Rembrandt's "Night Alarm" in "Fig. 4", they are regarded as the unique and excellent works in the world in anyone's eyes. Benjiamin mentioned in "Works of Art in the Age of Mechanical Reproduction" that to see more excellent works can cultivate their own aesthetic vision (Note 2). As for works like "Mona Lisa", "Spring" and "Night Alarm", people can feel the warmth of the colors, the thickness of the texture and the subtle changes in modeling that pursued by the painter even in the print work. Painting techniques in "Spring" inherited Tempera techniques in the Middle Ages that drawn on the wooden board. It was the work during the period that Italy is active in religious thoughts, containing both humanistic tendency and medieval mysterious color. Da Vinci's "Sfumato" is the main technique of the Renaissance. Da Vinci employed this delicate light and shade performance to display the smile of Mona Lisa, expressed his view of nature and outlook on life. In "Night Alarm", a large group portrait painting of Rembrandt, the representative painter of Baroque, the dark color caused people's misunderstanding, and it turned out to be a turning point in Rembrandt's life. The techniques of the three works were different. The painting techniques have undergone great changes after impressionism and schools after it. The change of techniques and the application of new materials brought about obvious changes in the visual effects of painting. A thorough understanding of the techniques of art works would help to better understand the art works of different periods.

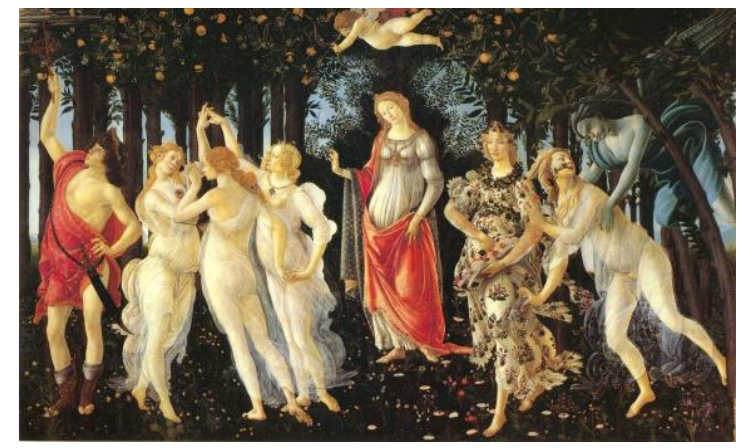

Fig. 3. Botticelli's "Spring".

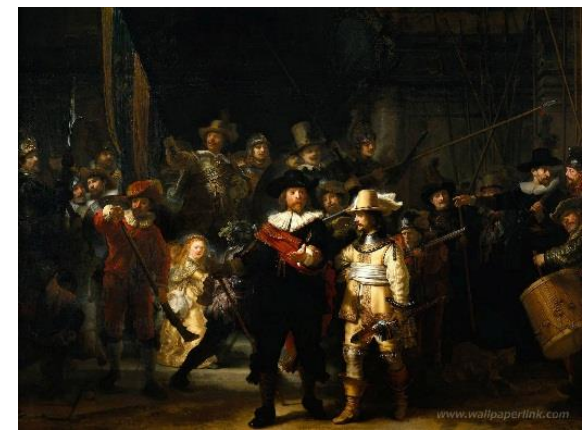

Fig. 4. Rembrandt "Night Alarm".

The color, luster, brush stroke, color overlapping and material texture effect of art works must be realized on the basis of direct observation of the original art works. Each artist will use these techniques very skillfully in his own work to paint a moving picture. This kind of moving requires the viewer to see the paintings in a close distance, and deeply understand the painter's creative background, feel the texture shown by the painter's painting techniques and painting materials. It is believed that this move should be permanently retained in the viewer's memory.

\section{CONCLUSION}

The appreciation education of art works is based on the mastery of the knowledge of social background and cultural origin of the work that created, and one should further understand the painter's career, biography reading, creative intention and purpose, etc. to obtain the ability of appreciating a piece of work. In fact, the understanding of traditional art also contains the part of history education. But these can not constitute all the elements of art appreciation. Art appreciation education is a part of students' overall quality growth and the formation of their world outlook. Art appreciation includes the understanding of beauty, such as aesthetics, spiritual and psychological behavior. The understanding of works and the painter is an indispensable element in the appreciation of visual plastic arts.

Art appreciation involves many aspects, including A. the painter; B. the work; C. the viewer; D. the educational institution or teacher who offers appreciation to the viewer; E. the purpose and course of appreciation education. There is a relationship between these five aspects. Art appreciation education should let the students feel the painter's personality through the works, and resonate with the painter's thinking, and arouse the viewer's sympathy and affection toward the inner symbolic content of the work. It is an important part in art appreciation education to respect the students' sensibility and appreciation ability of art appreciation and cultivate their initiative consciousness of participating in and paying attention to. (Note 3)

Art appreciation combines art history, art studies, psychology, aesthetics, sociology, philosophy and many other subjects. Art education is an important means to promote the perfection of individual and achieve the harmonious development of society. Lu Xun believed that art is helpful to moral education, "although the aim of art is different from 
morality, the power of art can help to cultivate people's temperament and elevate people's hobbies."(Note 4), and thus achieve the effect of "cultivating morality and governing the society". Especially in modern society, human relationship is becoming more superficial. Appreciation education of art works can improve people's quality and remedy the lack of modern civilization.

\section{REFERENCES}

[1] Panofsky, Studies in Iconology [M], translated by Qi Yinpig, Translations of Works on Art, Zhejiang Academy of Fine Arts Press, 1986: (4), 13.

[2] Takashina Shuji, Modern Art, [M], Kodansha, 1972:6

[3] Panofsky, Studies in Iconology [M], translated by Qi Yinpig, Translations of Works on Art, Zhejiang Academy of Fine Arts Press, 1986: (3), 26.

[4] Lu Xun, A Proposal for Art Communication, [M], http://blog.sina.com.cn/s/blog_6125e6320100nbnp.html. 